DOI: 10.12731/2077-1770-2019-2-212-227

УДК 141.3

\title{
КРИТИКА ЛИБЕРАЛЬНО-ДЕМОКРАТИЧЕСКОГО РАЗУМА. ДЕОНТОЛОГИЧЕСКАЯ ТЕОРИЯ ДЖ. РОЛЗА В СВЕТЕ ПРОБЛЕМЫ ПОЛИТИЧЕСКОЙ ИНТЕГРАЦИИ БЕЖЕНЦЕВ
}

\section{Фомин К.В.}

Цель. Статья посвящена ограничениям деонтологической теории в связи с проблемой политической интеграчии беженцев. В качестве предмета анализа выступает теория справедливости Дж. Ролза. Целью статьи является демонстрация постмаркситской теории справедливости как более эффективного инструмента в процессе политической интеграции беженцев.

Метод или методология проведения исследования. Основу исследования составляют критический, исторический и компаративистский методы.

Результаты. Автором были проанализировань философские предпосылки теории справедливости Дж. Ролза. К ним относится: правочентричный характер теории, помещение в основание договора абстрактного права на равенство, политический характер поздней теории. Далее в статье описываются нормативные ограничения теории справедливости последнего, связанные с процессом политической интеграции: непроясненность отношений между правами человека и гражданскими правами; формальная трактовка равенства; трактовка политики как прочесса согласования интересов. Автор представляет очерк постмаркситской теории справедливости. В коние статьи демонстрируется потенциал этой теории в разрешении проблемы политической интеграции беженцев.

Область применения результатов. Результаты исследования могут быть применень при разработке учебных курсов по соииальной и политической философии. 
Ключевые слова: деонтологическая теория; постмарксистская концепция равенства; беженцы; безгосударственные люди; права человека; гражданские права.

\section{CRITIQUE OF LIBERAL-DEMOCRATIC REASON. RAWLS'S DEONTOLOGICAL THEORY WITH REGARD TO THE PROBLEM OF REFUGEE'S POLITICAL INTEGRATION}

\section{Fomin K.V.}

Purpose. The article is devoted to normative constraints of deontological theory with regard to the problem of refugee's political integration. The subject of the analysis is Rawls's theory of justice. Author's purpose is to demonstrate the post-Marxist theory of justice as more productive tool for process of refugee's political integration.

Methodology. The research is based on critical, historical and comparative methods.

Results. The author explores philosophical premises of Rawls's theory of justice: rights-based character of theory, fundamental status of abstract right to equality, the political character of theory. Further, the paper explores normative constraints of theory of justice of American philosopher with regard to the problem of refugee's political integration: the confusion between human rights and civil rights; formal interpretation of equality; consensual interpretation of politics. The author presents the sketch of the post-Marxist theory of justice. At the end of the article, the potential of this theory for solving the problem of political integration of refugees is demonstrated.

Practical implications. Results of research can be applied for the development of courses in Social and Political Philosophy.

Keywords: deontological theory; post-Marxist conception of equality; refugee; stateless persons; human rights; civil rights.

С Первой мировой войны тема политической интеграции беженцев не потеряла актуальности. Ответом на проблему интеграции 
негосударственных людей стало появление Лиги Наций, в рамках которой была сформирована Комиссия по делам беженцев. Однако эта организация не достигла значительных результатов в области международной защиты беженцев. Её неэффективность была обусловлена рядом причин: отсутствие материальной базы, требующейся для финансирования дорогостоящих проектов по оказанию защиты беженцев и отсутствие системы международно-правовых соглашений в области вынужденной миграции. После Второй мировой войны проблема беженцев рассматривалась в 1946 г. в рамках первой сессии Генеральной Ассамблеи ООН. В качестве вспомогательного органа последней было создано Управление Верховного комиссара ООН по делам беженцев (УВКБ ООН). Система международной защиты беженцев с 1951 г. постепенно расширялась, и на сегодняшний день помимо вышеупомянутого органа ООН проблемой безгосударственных лиц занимаются межправительственные организации, среди которых можно назвать Международную организацию по миграции (МОМ), Детский фонд ООН (ЮНИСЕФ), Продовольственную и сельскохозяйственную организацию (ФАО), Всемирную организацию здравоохранения (ВО3).

Несмотря на расширение системы международной защиты прогресс в решении проблемы политической интеграции незначителен. Вместе с такими проблемами как миграция и гуманитарные интервенции, проблема увеличения лиц без гражданства усилила трение между правами человека и требованиями политических сообществ. В свете современной парадигмы прав человека, которую можно определить как «либеральную», беженцы представляются как наименее защищённая группа.

Принимая во внимание вышеизложенное, малое внимание политических мыслителей к вопросу о нормативном горизонте процесса интеграции безгосударственных лицах кажется парадоксальным. Среди немногих исследователей, признающих значимость этой проблемы можно назвать К. Бэнерджи [9], А. Бадью [8], С. Жижека [15] и некоторых теоретиков, занимающихся проблемами беженцев (refugeestudies). Вопреки этой общей тенденции мы стремимся переориентировать 
нормативную политическую теорию на конкретные затруднения и проблемы, связанные с безгосударственными лицами, ввиду того, что отсутствие внимания к позиции беженцев часто искажает или затемняет дискуссии о международных обязательствах и правах человека.

Нам представляется оправданным обращение к теории справедливости Дж. Ролза, объясняющей и упорядочивающей интуитивные представления о правильном и должном, которые стоят за международным правом и юридическими механизмами политической интеграции беженцев. Анализируя предпосылки этой теории мы совершаем своего рода «критику либерально-демократического разума». Проведенный анализ открывает пространство для иной теории справедливости, которая бы обеспечила подходящий для процесса политической интеграции беженцев нормативный горизонт. По мнению автора статьи, теория справедливости, разработанная с опорой на тексты постмарксистов, является оптимальным вариантом.

\section{Материалы и методы}

В исследовании мы будем опираться на следующие методологические предпосылки: 1) в рамках нашей статьи мы используем категории «безгосударственные лица» и «беженцы» как взаимозаменяемые; 2) принимается различие между политикой и политическим как различие между онтическим уровнем, т.е. уровнем конкретной социальной системы, определенной формы действия, уровнем на котором функционирует уже оформленный социальный порядок, и онтологическим уровнем, т.е. уровнем максимального антагонизма и одновременно уровнем, на котором закладывается основание нового, ранее ещё не существовавшего, порядка; 3) отрицается идея предзаданного политического субъекта.

\section{Результаты и обсуждение}

\section{Деонтологическая теория Дюк. Ролза и ее философские предпосылки}

Для понимания теории справедливости Дж. Ролза необходимо разобраться в трех фундаментальных моментах: контексте возник- 
новения, составных элементах и философских предпосылках. Последовательно рассмотрим каждый из этих моментов.

Теория справедливости Дж. Ролза возникла в контексте господства утилитаризма и интуитивизма в этической области. Сторонники первого направления либо придерживались миллевской точки зрения, согласно которой требования справедливости не вступают в конфликт с общественной пользой [5, с. 235], либо допускали этот конфликт и отдавали в нем приоритет общественной пользе. Но все они сходились в том, что базовым этическим принципом является общественная польза. Сторонники интуитивизма вопреки утилитаристам оспаривали саму возможность выделения базового этического принципа. Они полагали, что не существует единственно правильного разрешения моральных дилемм [10, p. 1007].

Теория справедливости Дж. Ролза разрабатывалась как альтернатива этим двум направлениям. Американский философ ставил перед собой следующие задачи:

1) обосновать интуитивное представление о том, что «права... не являются предметом политического торга или же калькуляции социальных интересов» $[6$, с. 38$]$;

2) сформулировать такую концепцию справедливости, которая «имела бы тенденцию к сходимости наших моральных суждений справедливости» [6, с. 51].

Прежде чем переходить к составным элементами теории справедливости Дж. Ролза, необходимо понять, какие ограничения накладывает на нее сам автор. Во-первых, теория американского философа затрагивает лишь вопрос справедливости базовых экономических и политических институтов. Дж. Ролз пишет: «Главный субъект справедливости базисная структура общества» [6, с. 22]. Во-вторых, американский философ ставит перед собой задачу описания структуры вполне упорядоченного общества, члены которого строго бы выполняли требования справедливости. По этой причине теорию Дж. Ролза можно определить как теорию строгого согласия («strict compliance theory»).

Перечислив ограничения, мы можем обратиться к основным элементам теории справедливости. К ним можно отнести: 
1. Договорная теория обоснования. Суть этой теории заключается в том, что принципами справедливости можно считать лишь те принципы, которым бы отдали предпочтение участники исходной позиции, разрабатывающие проект желаемой базовой структуры общества.

2. Теория, описывающая условия исходной позиции.

3. Принципы справедливости, выведенные из двух вышеупомянутых теорий. Речь идет о двух принципах:

1 - принципе равных свобод: «каждый индивид должен обладать равным правом в отношении наиболее общей системы равных основных свобод, совместимой с подобными системами свобод для всех остальных людей» [6, с. 88].

2 - принципе различия: «социальные и экономические неравенства должны быть организованы таким образом, что они одновременно

(a) ведут к наибольшей выгоде наименее преуспевших...

(b) делают открытыми для всех должности и положения в условиях честного равенства возможностей» $[6$, с. 352]. 4. Схематичное описание «базисной структуры» институтов и практик, которая соответствует принципам справедливости [10, p. 1013]. Обратимся к философским предпосылкам, на которые опирается теория Дж. Ролза. Первой предпосылкой является правоцентрический характер теории. Здесь мы используем типологию, предложенную Р. Дворкиным [4, с. 237]. Только правоцентрическая теория полностью согласуется с договорной теорией обоснования. Основная идея этой теории заключается в том, что у отдельных индивидов есть интересы, которые они имеют право защищать. При разработке правоцентрической теории было бы естественным попытаться определить те институты, на которые индивид наложил бы вето, пользуясь своими фундаментальными правами. Договор является подходящим инструментом для решения такой задачи.

Второй предпосылкой является помещение в основании договора абстрактного права на равенство. Это право является единственным, которое не может быть обосновано через исходную позицию. 
Оно уже изначально предполагается ею, если вспомнить цель, для которой использовалась завеса неведения. Этот инструмент рассматривался Дж. Ролзом как средство, которое должно свести возможность несправедливых преференций к нулю.

Наконец, необходимо отметить политической характер поздней теории Дж. Ролза, призванной рассматривать моральные интуиции граждан конституционных или либеральных демократий. Американский философ сужает оперативное поле теории справедливости [7, с. 78]. На первый план выходит проблема сосуществования коммунитаристских и некоммунитаристских групп, решение которой Дж. Ролз видит в идее перекрещивающегося консенсуса [13]. Важно отметить, что американский философ трактует политику как политику согласования интересов.

\section{Нормативный фундамент теории Дюс. Ролза}

\section{в свете проблемы политической интеграции беженцев}

Обратимся к вопросу возможности решения проблемы беженцев при принятии предпосылок деонтологической теории справедливости. Начнем с идеи естественных прав, лежащих в основании последней. Предположим, что права человека отличаются от гражданских прав. В таком случае беженцы подпадают под категорию людей, которые защищаются концепцией справедливости. Необходимо отметить, что в основании такой трактовки естественных прав лежит представление о субъекте, который способен признать себя жертвой, субъекте, нуждающемся в государственной защите [3, с. 22].

В теории Дж. Ролза субъект прав идет в паре сильным государством, способным гарантировать его права. Такое государство требует формирования крепкой гражданской идентичности, которая, согласно теории политической идентификации Э. Лакло и Ш. Муфф, образуется посредством проведения четкой политической границы между «нами» и «ними» [11, р. 69]. Именно представители категории беженцев и будут первыми кандидатами на статус «чужих».

Принимая помощь государственной власти, безгосударственные лица не исправляют, а усугубляют свою ситуацию. Они попадают во все большую зависимость от расположения государственных чи- 
новников. Чем более продолжительна государственная помощь, тем большей маргинализации подвергаются беженцы. Кроме того, их положение усугубляется негативным имиджем у граждан, которые видят в исключенных объект особой заботы государства.

Таким образом, деонтологический дискурс прав человека способствует усугублению положения беженцев, увеличивая их зависимость от государственной власти, воспроизводящей их исключение. Для решения проблемы беженцев требуется существенный пересмотр концепции «прав человека».

Если мы исходим из трактовки прав человека как идентичных гражданским правам, тогда беженцы исключаются не просто из категории людей, защищаемых концепцией справедливости, а вместе с этим и из категории людей вообще. Лица, лишенные гражданства, при отождествлении человека и гражданина превращаются, если мы используем категории Дж. Агамбена, в фигуру Homosacer, человека, сведенного к «голой жизни»[1]. Они лишаются статуса человека. Таким образом, при двух вышеизложенных трактовках естественных прав позиция подобная ролзовской накладывает ограничения на процесс политической интеграции беженцев.

Обратимся ко второй предпосылке теории, согласно которой абстрактное право на равенство является фундаментальным правом, лежащим в основании договора. Равенство, о котором Дж. Ролз пишет, можно трактовать двояко: в универсалистском и партикуляристском ключе. Универсалистская трактовка равенства строится на игнорировании неравного положения граждан и безгосударственных людей. Сохранению этого слепого пятна способствует рассмотрению статуса «беженцев» как временного, статуса тех, кто ещё не получил, но в ближайшее время получит новое гражданство. В данной трактовке равенства исключается сама возможность массового феномена безгосударственности и становится возможной задержка процесса получения гражданства на неопределенно долгий срок.

При партикуляристской трактовке равенства у должностных лиц и граждан национального государства появляется моральное оправдание игнорирования индивидуальных требований беженцев. Она 
открывает пространство для широкого спектра дискриминационных действий: от пренебрежения до открытой агрессии. Подобная трактовка равенства легитимизирует неравный статус граждан и безгосударственных лиц. Таким образом, ни универсалистская, ни партикуляристская трактовка равенства не будут способствовать решению проблемы беженцев.

Обратимся к последней предпосылке теории Дж. Ролза. Как нами уже было упомянуто, Дж. Ролз разрабатывает теорию строгого согласия. Отсюда становится понятно пренебрежение американского философа к конфликтному измерению общественного бытия. Даже когда он пишет про политику, он всегда подразумевает политику согласия.

Такое виденье предустановленной политической гармонии исключает любой действительный конфликт: Дж. Ролз и другие деонтологические либералы не могут помыслить беженцев как агентов, вовлеченных в эмансипационное движение. Изначально отрицается возможность занятия безгосударственными лицами, да и гражданами, активной позиции: включенность в борьбу за определение характера национального сообщества и участие в политических манифестациях, демонстрирующих их политическую способность. Таким образом, моральные постулаты теории Дж. Ролза не только не задают направление, в котором мы должны двигаться, чтобы найти набор институциональных мер для решения проблемы беженцев, но и исключают любую активную политическую деятельность безгосударственных лиц, которая способствовала бы их интеграции.

\section{Постмарксистская теория справедливости}

\section{как альтернатива деонтологической теории}

В нашей статье мы отдаем предпочтение трактовке категории «постмарксизм» С. Торми и Ж. Тауншенда. К категории «постмарксистов» они относят представителей критической теории, утверждающих, что марксизм находится в кризисе, и вместе с тем отстаивающих необходимость анализа работы и наследия Маркса для воссоздания критики и политического ответа развитому капитализму [14]. Категорию постмарксистов С. Торми и Ж. Тауншенд предлагают трактовать как открытую категорию, члены которой связаны друг с другом «фамильным сходством». 
Автор предполагает, что новая теории справедливости может быть разработана с опорой на тексты тех постмарксистов, которые предлагали тот или иной вариант теории революционной субъективности: Ж. Рансьера, А. Бадью, Э. Лакло и Ш. Муфф. Этим философам отдается предпочтение, так как каждый из них проблематизирует консенсуальный подход к политике и придает особое значение позиции тех, кто исключен из институционального оформленного иерархического порядка. Набросок такой теории будет представлен ниже.

Начнем с базовых предпосылок постмарксистской теории справедливости. Эта теория исходит из основополагающего факта неравенства. Согласно постмарксистской теории, люди изначально погружены в сеть социальных отношений власти и доминирования. Именно на фоне социального неравенства устанавливается и конституируется равенство, не гарантируемое рациональной природой человека или чем-то иным.

Данная теория исходит из перспективы угнетённых. Вместо индивидов и граждан Ж. Рансьер, А. Бадью, Э. Лакло и Ш. Муфф обращаются к тем, кто не обладает всей полнотой прав и не может воспользоваться всеми благами гражданства. Преимущество этой перспективы перед другими заключается в том, что она позволяет оценить масштабы системы доминирования и господства и роль, которую играют механизмы исключения в воспроизводстве социального целого.

Рассмотрев базовые предпосылки постмарксистской теории справедливости, мы обратимся к центральному элементу: концепции равенства. Можно выделить ряд общих черт, присущих постмарксистским концепциям равенства. Во-первых, Ж. Рансьер, А. Бадью, Э. Лакло и Ш. Муфф помещают вопрос равенства в контекст трансформационной и эмансипационной политики. Во-вторых, всех вышеупомянутых авторов объединяет критическое отношение к требованиям признания различия и желание уйти от постановки проблемы равенства только в культурном поле. В-третьих, постмарксисты реинтерпретируют равенство как исходный принцип политики: ранее трактовавшееся как положение дел, к которому надо стремиться, оно трансформируется в начальный пункт всякой преобразовательной деятельности активистов. 
Для дальнейшего развития концепцию равенства нам необходимо обратиться к вопросу о взаимосвязи между правами человека и правами гражданина. Одним из главных ориентиров для нас выступает текст Ж. Рансьера «Кто является субъектом прав человека?» [12]. В этом тексте французский философ переосмысливает понятие «прав человека». Критикуя подход Дж. Агамбена [1] и Х. Арендт [2] к правам человека, французский философ предлагает рассматривать это понятие как имя, не имеющее чёткого референта. Согласно Ж. Рансьеру, политика связана с инициацией тяжбы, на которой неучтенные заявляют о своем существовании, утверждают фундаментальное равенство каждого с каждым, апеллируя к правам человека. Эти неучтенные организуют спор по поводу границы между теми, кто имеет права, и теми, кто не имеет права участвовать в управлении. Выходит, что права человека трактуются как горизонт любой политической борьбы за расширение гражданских прав. Когда политический процесс заканчивается наделением исключённых всей полнотой прав, они уступают место гражданским правам, гарантируемые конкретным государством, до следующей политической манифестации.

Согласно точке зрения четырёх представителей постмарксистской мысли, теория справедливости не должна накладывать ограничений на политический процесс эмансипации, а максимально содействовать ему. Этому условию может отвечать лишь абстрактная концепция справедливости, в основание которой положена идея равенства как предпосылки, а не как цели, которую необходимо достичь. Важно отметить, что основанием такого подхода к отношению между теорией справедливости и политической практикой является постулат о существовании порядка человеческой свободы противоположного онтологическому порядку.

\section{Преодоление нормативных ограничений деонтологической теории Дюс. Ролза в рамках постмарксистской теории справедливости}

Первое препятствие преодолевается в рамках постмарксистской теории справедливости благодаря прояснению характера отношений между правами человека и гражданскими правами и превращению 
первых в категорию, лишенную четкого референта. Пересмотренная концепция прав человека уже неуязвима перед критическими аргументами, которые были направлены против либеральной концепции. В основании постмарксистской концепции прав лежит отказ от идеи индивида до гражданского состояния. Права человека - это права неучтенных в политическом сообеесве, которые подрывают само противопоставление индивидуальных и коллективных прав. В этой концепции потребность в правах человека связана с существующими осями доминирования: классом, полом, гендером, сексуальной ориентацией и т.д. Права человека, следовательно, больше не рассматриваются как игнорирующие или поддерживающие властные отношения. Они средство подрыва сложившихся иерархий и эффективный инструмент на пути установления более справедливых отношений. Эта концепция трактует права человека как активные права, которые не гарантированы никакой внешней инстанцией. Права человека - это не права уязвимого существа, нуждающегося в защите, это права политического активиста, демонстрирующего отсутствие различия между собой и теми, кто наделен всей полнотой прав. В пересмотренной концепции прав на место страдающей субъективности встает утверждающая субъективность.

В отличие от концепции прав в основании деонтологической концепции Дж. Ролза, постмарксистская концепция прав не будет способствовать маргинализации беженцев. Истолкованные таким образом права человека не нуждаются в сильной государственной власти и национальной идентичности. Они направлены на приостановку государственных механизмов иерархии и делигитимацию признаков, которые казались «естественно» присущими той или иной национальной идентичности. Таким образом, реинтерпретация прав как критического инструмента создает условия для политической интеграции беженцев.

Второе препятствие преодолевается в рамках постмарксистской теории справедливости благодаря трактовке равенства не как желаемой цели, а как исходной предпосылки политического процесса. Фокус смещается с обсуждения критериев равного распределения благ социальными институтами определенного политического сообщества на внутренний принцип политико-преобразовательной деятельности. 
Против такой концепции равенства уже нельзя использовать аргументы, которые выдвигались против либеральной трактовки. Опора на по-иному истолкованный универсализм позволяет постмарксистской концепции равенства избежать проблем, с которыми сталкивается концепция Дж. Ролза. Постмарксисты пишут не о пассивном равенстве, распространяющемся на всех жителей планеты Земля, а о безусловном равенстве в конкретном времени и в конкретном месте, которое поддерживается конкретной практической деятельностью.

Постмарксистская трактовка равенства как того, что устанавливается в контексте неравенства, в отличие от трактовки Дж. Ролза, не будет способствовать сокрытию неравного статуса беженцев по отношению к гражданам национальных государств. Она сможет содействовать политическому процессу, который вынесет на передний план их бедственное положение. Проблемы, связанные с действенными международными механизмами, гарантирующие равенство, при принятии постмарксистской перспективы становятся нерелевантными.

Третье препятствие преодолевается в постмарксистской теории справедливости благодаря тому, что она изначально предполагает конфликтное измерение. Возражения, выдвигаемые против трактовки политики Дж. Ролза, не могут быть выдвинуты против постмарксистской трактовки политики. Постмарксистские теоретики отрицают возможность установления чёткой границы между областью приватного и областью публичного. Линия между первой и второй областью рассматривается как смещающаяся под влиянием политической практики активистов. Такое виденье препятствует затвердеванию социальных иерархий. В основании постмарксистской теории справедливости лежит этика политического, а не политическая мораль. Постмарксистские теоретики изначально принимают во внимание конфликт по поводу определения облика политического сообщества и конфликт между учтёнными и неучтёнными.

Постмарксистская теория справедливости открывает путь к политической интеграции беженцев. Этот путь пролегает через участие неучтённых в публичных акциях. Они будут способство- 
вать формированию культуры конфликта, отказу от представления о замкнутом политическом сообществе в пользу представления о динамически развивающемся сообществе. На смену конфронтационной логике группового партикуляризма придет политическая логика спора по поводу включенных и исключенных из политического сообщества.

\section{Заключение}

С помощью сравнительного анализа нами были выявлены нормативные ограничения на пути решения проблемы политической интеграции беженцев, накладываемые теорией Дж. Ролза, и продемонстрировано, как они преодолеваются в постмарксистской теории справедливости. Первое препятствие, связанное с маргинализацией беженцев, преодолевается в рамках постмарксистской теории справедливости благодаря прояснению характера отношений между правами человека и гражданскими правами, а также превращению первых в категорию, лишённую чёткого референта. Второе препятствие, связанное с искажённой трактовкой статуса беженца, преодолевается в рамках постмарксистской теории справедливости благодаря трактовке равенства не как желаемой цели, а как исходной предпосылки политического процесса. Третье препятствие, связанное с исключением возможности участия беженцев в эмансипационном движении, преодолевается в постмарксистской теории справедливости благодаря тому, что она изначально предполагает конфликтное измерение.

\section{Список литературы}

1. Агамбен Дж. Ноmo Sacer. Суверенная власть и голая жизнь. М.: Европа, 2011. 256 с.

2. Арендт Х. Истоки тоталитаризма. М.: ЦентрКом, 1996. 672 с.

3. Бадью А. Этика: Очерк о сознании. СПб.: Machina, 2006. 126 с.

4. Дворкин Р. О правах всерьез. М.: Российская политическая энциклопедия (РОССПЭН), 2004. 392 с.

5. Милль Дж. С. Утилитаризм. Ростов-на-Дону: Донской издательский дом, 2013. 240 с. 
6. Ролз Дж. Теория справедливости. Новосибирск: Изд-во Новосиб. ун-та, 1995. 535 с.

7. Рикер П. Справедливое. М.: Гнозис, 2005. 304 с.

8. Badiou A. Our Wound is Not So Recent: Thinking the Paris Killings of 13 November. Cambridge, UK; Malden, MA: Polity Press, 2016. 80 p.

9. Banerjee K. Re-theorizing Human Rights through the Refugee: On the Interrelation Between Democracy and Global Justice // Refuge: Canada’s Periodical on Refugees. 2010. Vol. 27. № 1, pp. 24-35.

10. Feinberg J. Justice, Fairness and rationality Joel Feinberg, Justice, Fairness and Rationality // Yale Law Journal. 1972. Vol. 81. № 5, pp. 1004-1031.

11. Mouffe, C. The return of the political. London: Verso, 2005. 240 p.

12. Ranciere J. Who Is the Subject of the Rights of Man? // The South Atlantic Quarterly. 2004. Vol. 103, № 2/3, pp. 297-310.

13. Rawls J. On the Idea of an Overlapping Consensus // Oxford Journal for Legal Studies. 1987. Vol. 7, № 1, pp. 1-25.

14. Tormey S. Key Thinkers from Critical Theory to Post-Marxism. London: Sage Publications, 2006. 240 p.

15.Žižek S. Against the Double Blackmail: Refugees, Terror and Other Troubles with the Neighbors. United Kingdom: Allen Lane, 2016.

\section{References}

1. Agamben J. Homo Sacer. Suverennaya vlast'i golaya zhizn' [Homo Sacer. Sovereign power and naked life]. M.: Evropa, 2011. 256 p.

2. Arendt X. Istoki totalitarizma [The origins of totalitarianism]. M.: TsentrKom, 1996. 672 p.

3. Bad'yu A. Etika: Ocherk o soznanii [Ethics: Essay on consciousness]. SPb.: Machina, 2006. 126 p.

4. Dvorkin R. O pravakh vser'ez [On rights in earnest]. M.: Rossiyskaya politicheskaya entsiklopediya (ROSSPEN), 2004. 392 p.

5. Mill J. C. Utilitarizm [Utilitarianism]. Rostov-na-Donu: Donskoy izdatel'skiy dom, 2013. 240 p.

6. Rawls J. Teoriya spravedlivosti [Theory of justice]. Novosibirsk: Izd-vo Novosib. un-ta, 1995. $535 \mathrm{p}$.

7. Riker P. Spravedlivoe [Fair]. M.: Gnozis, 2005.304 p. 
8. Badiou A. Our Wound is Not So Recent: Thinking the Paris Killings of 13 November. Cambridge, UK; Malden, MA: Polity Press, 2016. 80 p.

9. Banerjee K. Re-theorizing Human Rights through the Refugee: On the Interre-lation Between Democracy and Global Justice. Refuge: Canada's Periodical on Refugees. 2010. Vol. 27. № 1, pp. 24-35.

10. Feinberg J. Justice, Fairness and rationality Joel Feinberg, Justice, Fairness and Rationality. Yale Law Journal. 1972. Vol. 81. № 5, pp. 1004-1031.

11. Mouffe C. The return of the political. London: Verso, 2005. 240 p.

12. Ranciere J. Who Is the Subject of the Rights of Man? The South Atlantic Quarterly. 2004. Vol. 103, № 2/3, pp. 297-310.

13. Rawls J. On the Idea of an Overlapping Consensus. Oxford Journal for Le-gal Studies. 1987. Vol. 7, № 1, pp. 1-25.

14. Tormey S. Key Thinkers from Critical Theory to Post-Marxism. London: Sage Publications, 2006. 240 p.

15.Žižek S. Against the Double Blackmail: Refugees, Terror and Other Troubles with the Neighbors. United Kingdom: Allen Lane, 2016.

\section{ДАННЫЕ ОБ АВТОРЕ}

Фомин Константин Валерьевич, ассистент кафедры философии и социологии

Северный (Арктический) федеральный университет имени М.В. Ломоносова

Набережная Северной Двины, 17, г. Архангельск, 163002, Российская Федерация

kostyafominphil@gmail.com

\section{DATA ABOUT THE AUTHOR}

Fomin Konstantin Valeryevich, Assistant of the department of Philosophy and Sociology

Northern Arctic Federal University named after M.V. Lomonosov 17, Severnaya Dvina Emb., Arkhangelsk, 163002, Russian Federation kostyafominphil@gmail.com

SPIN-code: 7955-3647

ORCID: 0000-0001-9448-340X 